\title{
Impact of the Body Mass Index on Hemorrhage After Surgery for Thyroid Cancer
}

This article was published in the following Dove Press journal:

Cancer Management and Research

\section{Peng Li $\mathbb{D}^{\prime}$ \\ Ruihua Luo' \\ Lanwei Guo ${ }^{2}$ \\ Wenlu $\mathrm{Li}^{3}$ \\ Jinxing $Q i^{1}$}

'Department of Head Neck and Thyroid Surgery, Affiliated Cancer Hospital of Zhengzhou University, Zhengzhou, Henan, People's Republic of China; ${ }^{2}$ Office for Cancer Control and Research, Affiliated Cancer Hospital of Zhengzhou University, Zhengzhou, Henan, People's Republic of China; ${ }^{3}$ Department of Oral and Maxillofacial Surgery, First Affiliated Hospital of Zhengzhou University, Zhengzhou, Henan, People's Republic of China
Correspondence: Peng Li Department of Head Neck and Thyroid Surgery, Affiliated Cancer Hospital of Zhengzhou University, 127 Dongming Road, Jinshui District, Zhengzhou 450008, Henan, People's Republic of China Email zlyylipeng2383@zzu.edu.cn
Objective: To investigate the effects of different values of the body mass index (BMI) on postoperative hemorrhage (PH) in thyroid cancer (TC) and its clinical management.

Methods: This retrospective cohort study selected 43 patients with hemorrhage after TC surgery in 7413 cases. Patients were divided based on the BMI $\left(\mathrm{kg} / \mathrm{m}^{2}\right)$ into normal (24), overweight group $(24 \leq \mathrm{BMl}<28)$ and obese $(\geq 28)$ groups. Clinical and pathologic data, bleeding cause, bleeding site, treatment and prognosis were assessed.

Results: $\mathrm{BMI}(P=0.038)$ is an independent risk factor for $\mathrm{PH}$ of $\mathrm{TC}$, related to hypertension ( $P=0.004)$ and coronary heart disease $(P=0.001)$ in the three groups. Preoperative weight loss was not noted $(P=0.477)$. Hemorrhage in $60.47 \%$ of patients occurred between $4 \mathrm{~h}$ and 8 $\mathrm{h}$ after surgery. The higher the BMI, the longer was the operative time ( $\geq 1 \mathrm{~h}, 65.12 \%$ ) $(P=0.017)$, which resulted in greater intraoperative blood loss $(\geq 20 \mathrm{~mL}, 74.42 \%)(P=0.025)$, postoperative hypoparathyroidism $(P=0.015)$ and the probability of injury to the recurrent laryngeal nerve $(P=0.026)$. The main causes of bleeding were incomplete vascular ligation (30.23\%), severe postoperative cervical activity (16.28\%) and long-term use of anticoagulant drugs $(11.63 \%)$. Overall survival at 5 years in the obese group was poor $(P=0.015)$. Forty patients $(93.02 \%)$ underwent surgical exploration and hemostasis and two patients $(4.65 \%)$ underwent tracheotomy. All PH complications disappeared completely after active postoperative treatment, and all patients were discharged from hospital.

Conclusion: Obesity is closely associated with PH in TC patients. Therefore, in obese patients, active prevention preoperatively, complete hemostasis intraoperatively, early detection and timely treatment postoperatively are the key factors to reduce PH risk.

Keywords: body mass index, thyroid cancer, hemorrhage

\section{Introduction}

In recent years, with the increasing number of obese patients, the incidence of thyroid cancer (TC) has been increasing rapidly worldwide, especially in China and South Korea. ${ }^{1}$ Non-Communicable Diseases Risk Factor Collaboration ${ }^{2}$ published a survey of 19.2 million people and showed that the prevalence of overweight and obese adults had increased to $\sim 40 \%$. The same pattern of increase has fueled the concern of several scholars ${ }^{3,4}$ with regard to the relationship between obesity and TC. However, most relevant research has focused on the incidence and mechanism: the effect of obesity on postoperative complications and survival has not been reported.

As first-line treatment for TC, surgery is essential to improve the chance of cure. However, with the increasing number of surgical procedures for $\mathrm{TC}$, the increasing number of postoperative complications has attracted attention. ${ }^{5,6}$ Due to the 
characteristics of a thyroid gland-rich blood supply, postoperative hemorrhage $(\mathrm{PH})$ is one of the main complications of TC surgery, and some patients may suffer from dyspnea (or even asphyxia). Several deaths caused by $\mathrm{PH}$ have been reported. ${ }^{7}$

Surgical procedures on obese patients can be challenging with respect to separation of fat and exposure of the region of interest; long duration of the procedure and induction of anesthesia time; greater intraoperative bleeding; obvious tissue swelling after surgery.

We assessed 43 patients with PH from 7413 TC cases in the past 5 years. We examined the relationship between obesity and PH between patients with different body mass index (BMI) values, focusing particularly on the reason, location and treatment for bleeding, as well as the outcome of surgery. We wished to provide valuable data for preoperative assessment as well as intraoperative and postoperative management strategies for the growing number of obese people suffering from TC worldwide.

\section{Patients and Methods}

\section{Ethical Approval of the Study Protocol}

The study protocol was approved by the Ethics Committee of the Affiliated Tumor Hospital of Zhengzhou University (Zhengzhou, China).

\section{Inclusion Criteria}

We collected general information on the surgical procedure, patient progress, and nursing records. If the patient had one of the following features, he/she was judged to have suffered PH: (i) rapid swelling under the skin, possibly accompanied by rapid, difficult breathing; (ii) drainage fluid $>60 \mathrm{~mL} / \mathrm{h}$, and the drainage fluid was coagulable; (iii) progressive swelling under the skin accompanied by subcutaneous ecchymosis, possibly accompanied by breathing difficulties; (iv) no swelling under the skin, progressive dyspnea, and exclusion of bilateral recurrent laryngeal nerve (RLN) injury.

\section{General Information}

We selected the data of 7413 patients with TC who underwent surgical treatment of the head and neck at the Affiliated Cancer Hospital of Zhengzhou University from January 2010 to January 2015, contain age, sex, BMI, diabetes mellitus, TC family history, radioactive radiation, Iodized salt intake, Hashimoto's Thyroiditis and so on, which considered to be risk factors for TC. ${ }^{8,9}$ We found
43 patients who suffered $\mathrm{PH}$. Clinical and pathology data, the cause and site of $\mathrm{PH}$, treatment, and 5-year survival of the 43 patients were analyzed. All patients were followed up at the same time interval. The BMI was based on the clinical information obtained for each patient in his/her medical notes. Based on the BMI (in $\mathrm{kg} / \mathrm{m}^{2}$ ), these 43 patients were divided into "normal" $(<24)$, "overweight" (24 $\leq$ BMI $<28)$ and "obese" $(\geq 28)$ groups according to BMI values for Chinese patients set by the World Health Organization. ${ }^{10}$

\section{Follow-Up}

Each patient was reviewed regularly after surgery for $\geq 5$ years. All patients were followed up to 1 November 2019 or had died by that time. Cases were reviewed every 3 months in the first year after surgery, every 6 months in the second year, and annually from the third year. If discomfort was felt during follow-up, patients could be seen in outpatient clinics at any time. The DocLink ${ }^{\mathrm{TM}}$ database and outpatient appointment follow-up were used to record data at each time point. Data were checked twice independently by two experienced head-and-neck surgeons to ensure data accuracy. The general characteristics and clinical data of the study cohort are shown in Tables 1 and 2.

\section{Statistical Analyses}

Data were analyzed using SPSS 17.0 (IBM, Armonk, NY, USA). Differences between normal, overweight, and obese groups were evaluated by the Kruskal-Wallis test. The rank-sum test was carried out for comparison of group pairs of continuous variables. Fisher's exact or chisquared tests were undertaken for categorical variables. $P<0.05$ was considered significant.

\section{Results}

Among 7413 patients data collected in our study, 43 cases have $\mathrm{PH}$. BMI $(P=0.038)$ is an independent risk factor for PH of TC, different to age $(P=0.641)$, sex $(P=0.208)$, diabetes mellitus ( $P=0.469)$, TC family history $(P=0.491)$, radioactive radiation $(P=0.339)$, Iodized salt intake $(P=0.534)$, Hashimoto's Thyroiditis $(P=0.245)$, which initially considered to be risk factors for $\mathrm{TC}^{8,9}$ (Table 1). Of the $43 \mathrm{PH}$ patients enrolled, 21 were in the normal group (48.84\%), 13 in the overweight group (30.23\%) and 9 in the obese group (20.93\%) (Table 2). Among them, 34 (79.07\%) were female, 9 cases (20.93\%) were male, and the ratio of males:females was 1:3.7, which is slightly higher to that reported in other studies. ${ }^{5,11}$ 
Table I Univariate Analysis of Risk Factors in 74I3 Patients with TC Open Operation

\begin{tabular}{|c|c|c|c|c|c|}
\hline Risk Factors & All $(N=74 \mid 3)$ & PH $(\mathrm{N}=43)$ & No $\mathrm{PH}(\mathrm{N}=7370)$ & $\chi^{2}$ & $P$ \\
\hline \multicolumn{6}{|l|}{ Age (Years) } \\
\hline$\geq 55$ & $3187(42.99 \%)$ & $20(46.51 \%)$ & $3167(42.97 \%)$ & & \\
\hline$<55$ & $4226(57.01 \%)$ & 23(53.49\%) & $4203(57.03 \%)$ & 0.217 & $0.64 I$ \\
\hline \multicolumn{6}{|l|}{ Sex } \\
\hline Female & $5762(77.73 \%)$ & $30(69.77 \%)$ & $5732(77.77 \%)$ & & \\
\hline Male & $|65|(22.27 \%)$ & $13(30.23 \%)$ & $1638(22.23 \%)$ & $\mathrm{I} .583$ & 0.208 \\
\hline \multicolumn{6}{|l|}{ BMI $\left(\mathrm{kg} / \mathrm{m}^{2}\right)$} \\
\hline Obesity (BMI $\geq 28)$ & |487(20.06\%) & $9(20.93 \%)$ & $719(9.76 \%)$ & & \\
\hline Overweight $(24 \leq \mathrm{BMI}<28)$ & $3329(44.91 \%)$ & $13(30.23 \%)$ & $2144(29.08 \%)$ & & \\
\hline Normal (<24) & $2597(35.03 \%)$ & $21(48.84 \%)$ & $4507(61.15 \%)$ & 6.517 & 0.038 \\
\hline \multicolumn{6}{|l|}{ Diabetes Mellitus } \\
\hline Yes & 646(8.71\%) & $5(11.63 \%)$ & $64 I(8.70 \%)$ & & \\
\hline No & $6767(91.29 \%)$ & $38(88.37 \%)$ & $6729(91.30 \%)$ & 0.462 & 0.469 \\
\hline \multicolumn{6}{|l|}{ TC Family History } \\
\hline Yes & $352(4.75 \%)$ & $3(6.98 \%)$ & $349(4.74 \%)$ & & \\
\hline No & $706 \mid(95.25 \%)$ & $40(93.02 \%)$ & $7021(95.26 \%)$ & 0.475 & 0.491 \\
\hline \multicolumn{6}{|l|}{ Radioactive Radiation } \\
\hline Yes & $69(0.93 \%)$ & $\mathrm{I}(2.33 \%)$ & $68(0.92 \%)$ & & \\
\hline No & 7344(99.07\%) & $42(97.67 \%)$ & 7302(99.08\%) & 0.912 & 0.339 \\
\hline \multicolumn{6}{|l|}{ Hashimoto's Thyroiditis } \\
\hline Yes & $3483(46.99 \%)$ & $24(55.81 \%)$ & $3459(46.93 \%)$ & & \\
\hline No & $3930(53.01 \%)$ & $19(44.19 \%)$ & $3911(53.06 \%)$ & 1.353 & 0.245 \\
\hline \multicolumn{6}{|l|}{ Hyperthyroidism } \\
\hline Yes & $142(1.92 \%)$ & $0(0 \%)$ & $142(1.93 \%)$ & & \\
\hline No & $727 \mid(98.08 \%)$ & $43(100 \%)$ & 7228(98.07\%) & 0.839 & 0.360 \\
\hline \multicolumn{6}{|l|}{ lodized Salt Intake (g/day) } \\
\hline$\geq 10$ & $3798(51.23 \%)$ & $20(46.51 \%)$ & $3778(51.26 \%)$ & & \\
\hline$<10$ & $3615(48.77 \%)$ & $23(53.49 \%)$ & $3592(48.74 \%)$ & 0.386 & 0.534 \\
\hline
\end{tabular}

Abbreviations: $\mathrm{PH}$, postoperative hemorrhage; TC, thyroid cancer; BMI, body mass index.

The prevalence of hypertension $(P=0.004)$ and coronary heart disease $(\mathrm{CHD})(P=0.001)$ was significantly different between the three groups. Compared with patients in the normal group, the overweight group and obese group did not show weight loss after surgery, which is different to the situation after surgery for esophageal cancer, colorectal cancer and other tumors closely related to digestion. Papillary carcinoma accounted for $88.37 \%$ of cases, which is slightly lower than that reported by other scholars. ${ }^{6,11}$ Two reasons that may account for this difference could be the late enrolment of patients and differences between the sexes. We found that T3/T4 stage accounted for nine cases $(20.93 \%)$ in the T stage, M1 for six cases (13.95\%) in the M stage, and III/IV for eight cases $(18.60 \%)$ in the clinical stage, which are higher than that reported in the literature. ${ }^{11,12}$ However, the pathology type $(P=0.842)$, T stage $(0.488), \mathrm{N}$ stage $(0.722), \mathrm{M}$ stage (0.958), and clinical stage (0.919) did not show significant differences, or indeed diabetes mellitus (0.071) (Table 2).

In 26 cases $(60.47 \%)$, hemorrhage occurred between $4 \mathrm{~h}$ and $8 \mathrm{~h}$ after surgery. Regardless of the BMI group, there were no significant differences between them $(P=0.095)$. However, hemorrhage within $4 \mathrm{~h}(P=0.039)$ and after $8 \mathrm{~h}(P=0.012)$ each group was significantly different, and this may have been because observation of $\mathrm{PH}$ in obese patients early after surgery is difficult. The higher the BMI, the longer was the surgical procedure ( $\geq 1 \mathrm{~h}, 65.12 \%$ ) $(P=0.017)$, which resulted in greater intraoperative blood loss $(\geq 20 \mathrm{~mL}, 74.42 \%)(P=0.025)$ and a higher prevalence of hypoparathyroidism $(P=0.015)$ and RLN injury $(P=0.026)$. However, we found no significant difference in 
Table 2 General Characteristics and Clinical Data of 43 Patients with Hemorrhage After TC Surgery

\begin{tabular}{|c|c|c|c|c|c|c|}
\hline Clinicopathological Variable & All $(\mathrm{N}=43)$ & Normal $(\mathbf{N}=\mathbf{2} I)$ & Overweight $(\mathrm{N}=13)$ & Obese $(\mathrm{N}=9)$ & $\chi^{2}$ & $P$ \\
\hline \multicolumn{7}{|l|}{ Age (Years) } \\
\hline$\geq 55$ & 19 (44.19\%) & $9(42.86 \%)$ & $5(38.46 \%)$ & $5(55.56 \%)$ & & \\
\hline$<55$ & $24(55.8 \mid \%)$ & $12(57.14 \%)$ & $8(61.54 \%)$ & 4 (44.44\%) & 0.660 & 0.719 \\
\hline \multicolumn{7}{|l|}{ Sex } \\
\hline Female & 34 (79.07\%) & 17 (80.95\%) & 10 (76.92\%) & 7 (77.78\%) & & \\
\hline Male & 9 (20.93\%) & $4(19.05 \%)$ & $3(23.07 \%)$ & $2(22.22 \%)$ & 0.090 & 0.956 \\
\hline \multicolumn{7}{|l|}{ Hypertension } \\
\hline Yes & $8(18.60 \%)$ & I (4.76\%) & $2(15.38 \%)$ & $5(55.56 \%)$ & & \\
\hline No & $35(81.40 \%)$ & $20(95.24 \%)$ & II (84.62\%) & $4(44.44 \%)$ & 10.861 & 0.004 \\
\hline \multicolumn{7}{|l|}{ Weight Loss } \\
\hline Yes & $2(4.65 \%)$ & I (4.76\%) & $0(0.00 \%)$ & I (II.II\%) & & \\
\hline No & 41 (95.35\%) & $20(95.24 \%)$ & $13(100.00 \%)$ & 8 (88.89\%) & 1.482 & 0.477 \\
\hline \multicolumn{7}{|l|}{ Diabetes Mellitus } \\
\hline Yes & $5(11.63 \%)$ & I (4.76\%) & I (7.69\%) & $3(33.33 \%)$ & & \\
\hline No & $38(88.37 \%)$ & 20 (95.24\%) & $12(92.31 \%)$ & $6(66.67 \%)$ & 5.286 & 0.071 \\
\hline \multicolumn{7}{|l|}{ CHD } \\
\hline Yes & 7 (I6.28\%) & I (4.76\%) & I (7.69\%) & $5(55.56 \%)$ & & \\
\hline No & 36 (83.72\%) & 20 (95.24\%) & 12 (92.3।\%) & 4 (44.44\%) & 13.774 & 0.001 \\
\hline \multicolumn{7}{|l|}{ Pathology } \\
\hline PTC & 38 (88.37\%) & I8 (85.7।\%) & $12(92.31 \%)$ & 8 (88.89\%) & & \\
\hline Other & $5(11,63 \%)$ & 3 (I4.29\%) & I (7.69\%) & I (II.II\%) & 0.343 & 0.842 \\
\hline \multicolumn{7}{|l|}{ T Stage } \\
\hline TI/T2 & 34 (79.07\%) & I8 (85.7।\%) & 10 (76.92\%) & $6(66.67 \%)$ & & \\
\hline T3/T4 & 9 (20.93\%) & $3(14.29 \%)$ & $3(23.07 \%)$ & $3(33.33 \%)$ & 1.433 & 0.488 \\
\hline \multicolumn{7}{|l|}{ N Stage } \\
\hline No & 14 (32.56\%) & 7 (33.33\%) & $5(38.46 \%)$ & 2 (22.22\%) & & \\
\hline $\mathrm{NI}$ & 29 (67.44\%) & 14 (66.67\%) & 8 (61.54\%) & 7 (77.78\%) & 0.650 & 0.722 \\
\hline \multicolumn{7}{|l|}{ M Stage } \\
\hline Mo & 37 (86.05\%) & |8 (85.7।\%) & II (84.62\%) & 8 (88.89\%) & & \\
\hline MI & 6 (13.95\%) & $3(14.29 \%)$ & 2 (I5.38\%) & I (II.II\%) & 0.085 & 0.958 \\
\hline \multicolumn{7}{|l|}{ Clinical Stage } \\
\hline I / II & 35 (8I.40\%) & 17 (80.95\%) & II (84.62\%) & 7 (77.78\%) & & \\
\hline III/IV & 8 (I8.60\%) & $4(19.05 \%)$ & 2 (15.38\%) & 2 (22.22\%) & 0.170 & 0.919 \\
\hline
\end{tabular}

Abbreviations: CHD, coronary heart disease; PTC, papillary thyroid carcinoma.

the prevalence of injury to the superior laryngeal nerve $(P=0.093)$ or additional radionuclide therapy after surgery $(P=0.383)$ in any group. During follow-up, OS at 5 years was $90.70 \%$, and four deaths occurred (three of whom were in the obese group). The pathology of these deaths was undifferentiated cancer (1 case), medullary thyroid cancer (1 case) and papillary thyroid cancer ( 2 cases). The cause of death was due to complications of advanced TC: two patients died due to multiple-organ failure caused by systemic multiple- organ failure; one died due to massive hemorrhage caused by vascular invasion; one died of respiratory failure caused by lung metastasis (Table 3).

With regard to $\mathrm{PH}$ causes, $\mathrm{PH}$ sites and treatment, we adopted a paired-analysis of the three groups (Tables 4 and 5). Incomplete vascular ligation (i.e., absence of ligation, loose ligation, or loss of ligation thread) accounted for $30.23 \%$ of PH causes. Severe postoperative cervical activity, such as nausea, vomiting and cough, was observed in 
Table 3 Treatment and Outcome After TC Surgery

\begin{tabular}{|c|c|c|c|c|c|c|}
\hline Treatment and Outcome & Total $(\mathrm{N}=43)$ & Normal $(\mathbf{N}=\mathbf{2} I)$ & Overweight $(\mathrm{N}=13)$ & Obese $(\mathrm{N}=9)$ & $\chi^{2}$ & $\mathbf{P}$ \\
\hline \multicolumn{7}{|l|}{ Time of Bleeding $(h)$} \\
\hline Within 4 & II (25.58\%) & 9 (42.86\%) & I (7.69\%) & I (II.II\%) & 6.467 & 0.039 \\
\hline Between 4 and 8 & $26(60.47 \%)$ & II (52.38\%) & II (84.62\%) & $4(44.44 \%)$ & 4.712 & 0.095 \\
\hline After 8 & $6(13.95 \%)$ & I (9.52\%) & I (7 0.69\%) & 4 (44.44\%) & 8.871 & 0.012 \\
\hline \multicolumn{7}{|l|}{ Duration of Surgery (h) } \\
\hline$\geq 1$ & $28(65.12 \%)$ & $9(42.86 \%)$ & II (84.62\%) & 8 (88.89\%) & & \\
\hline$<1$ & $15(34.88 \%)$ & $12(57.14 \%)$ & $2(15.38 \%)$ & I (II.II\%) & 8.110 & 0.017 \\
\hline \multicolumn{7}{|l|}{ Intraoperative Blood Loss (mL) } \\
\hline$\geq 20$ & 29 (74.42\%) & $10(47.62 \%)$ & II (84.62\%) & $8(88.89 \%)$ & & \\
\hline$<20$ & 14 (25.58\%) & II (52.38\%) & $2(15.38 \%)$ & I (I I.II\%) & 7.389 & 0.025 \\
\hline \multicolumn{7}{|l|}{ Lateral Neck Dissection } \\
\hline Yes & 15 (34.88\%) & 7 (33.33\%) & $4(30.77 \%)$ & 4 (44.44\%) & & \\
\hline No & $28(65.12 \%)$ & $14(66.67 \%)$ & 9 (69.23\%) & $5(55.56 \%)$ & 0.544 & 0.762 \\
\hline \multicolumn{7}{|l|}{ Other Complications } \\
\hline Hypoparathyroidism & 9 (20.93\%) & 2 (19.04\%) & $2(15,38 \%)$ & $5(55.56 \%)$ & 8.412 & 0.015 \\
\hline RLN injury & 7 (18.60\%) & I (9.52\%) & $2(15.38 \%)$ & $4(44.44 \%)$ & 7.290 & 0.026 \\
\hline SLN injury & $4(9.30 \%)$ & $2(19.04 \%)$ & I (7.69\%) & I (II.II\%) & 0.076 & 0.963 \\
\hline \multicolumn{7}{|l|}{ Nuclide II3I Treatment } \\
\hline Yes & $23(53.49 \%)$ & $12(57.14 \%)$ & 5 (38.46\%) & $6(66.67 \%)$ & & \\
\hline No & $20(46.51 \%)$ & $9(42.86 \%)$ & $8(61.54 \%)$ & $3(33.33 \%)$ & 1.921 & 0.383 \\
\hline \multicolumn{7}{|l|}{ 5-Year Overall Survival } \\
\hline Yes & 39 (90.70\%) & $21(100.00 \%)$ & $12(92.31 \%)$ & $6(66.67 \%)$ & & \\
\hline No & $4(9.30 \%)$ & $0(0.00 \%)$ & I (7.69\%) & $3(33.33 \%)$ & 8.354 & 0.015 \\
\hline
\end{tabular}

Abbreviations: RLN, recurrent laryngeal nerve; SLN, superior laryngeal nerve.

Table 4 Statistical Analyses for 43 Cases of Hemorrhage After TC Surgery

\begin{tabular}{|c|c|c|c|c|c|}
\hline Cause of Bleeding & $\begin{array}{l}\text { Total } \\
(\mathrm{N}=43)\end{array}$ & $\begin{array}{l}\text { Normal } \\
(\mathrm{N}=2 \mathrm{I})\end{array}$ & $\begin{array}{l}\text { Overweight } \\
(\mathrm{N}=13)\end{array}$ & $\begin{array}{l}\text { Obese } \\
(\mathrm{N}=9)\end{array}$ & $P$ \\
\hline \multicolumn{6}{|l|}{ Operator Factors } \\
\hline Incomplete vascular ligation & 13 & 8 & 2 & 3 & $a=0.803 ; b=0.157$ \\
\hline Incomplete suture of the thyroid stump & 3 & I & I & I & $a=0.523 ; b=0.723$ \\
\hline Closure of energy device & 4 & 2 & I & I & $a=0.834 ; b=0.916$ \\
\hline Inappropriate drainage tube & 2 & I & $\mathrm{I}$ & 0 & $a=0.724 ; b=0.249$ \\
\hline \multicolumn{6}{|l|}{ Patient Factors } \\
\hline Taking anticoagulant drugs or coagulopathy & 5 & I & I & 3 & $a=0.035 ; b=0.724$ \\
\hline Huge tumor or secondary surgery & 3 & 2 & I & 0 & $a=0.338 ; b=0.856$ \\
\hline Severe postoperative cervical activity & 7 & 3 & 2 & 2 & $a=0.593 ; b=0.929$ \\
\hline \multicolumn{6}{|l|}{ Other Factors } \\
\hline Anesthesia for extubating & 4 & I & I & I & $a=0.523 ; b=0.724$ \\
\hline Improper position of drainage device & 2 & I & I & 0 & $a=0.506 ; b=0.724$ \\
\hline Aggressive removal of a drainage tube & 1 & I & 0 & 0 & $a=0.506 ; b=0.424$ \\
\hline
\end{tabular}

Notes: Five patients-each had two reasons for postoperative hemorrhage. a: Obese group vs normal group; b: overweight group vs normal group.

$16.28 \%$ of cases. Long-term use of anticoagulant drugs (e.g., aspirin) or coagulopathy accounted for $11.63 \%$ of cases (mostly in the obese group, $P=0.035$ ) but a significant difference between the overweight group and normal group was not observed $(P=0.724)$. Bleeding of the branch of the RLN passing into the larynx was noted in $25.58 \%$ of 
Table 5 Statistical Analyses of Bleeding Sites and Treatment Methods for 43 TC Patients

\begin{tabular}{|c|c|c|c|c|c|}
\hline Bleeding Site/Treatment & $\begin{array}{l}\text { Total } \\
(N=43)\end{array}$ & $\begin{array}{l}\text { Normal } \\
(\mathrm{N}=2 \mathrm{I})\end{array}$ & $\begin{array}{l}\text { Overweight } \\
(\mathrm{N}=13)\end{array}$ & $\begin{array}{l}\text { Obese } \\
(\mathrm{N}=9)\end{array}$ & $\boldsymbol{P}$ \\
\hline \multicolumn{6}{|l|}{ Bleeding Site } \\
\hline RLN into the larynx & 11 & 4 & 3 & 4 & $a=0.149 ; b=0.777$ \\
\hline Anterior cervical vein & 6 & 3 & 2 & 1 & $a=0.815 ; b=0.929$ \\
\hline TPM nourishing vein & 2 & 0 & $\mathrm{I}$ & I & $a=0.012 ; b=0.197$ \\
\hline Branch of the internal jugular vein & 5 & 2 & 2 & 1 & $a=0.893 ; b=0.606$ \\
\hline Branch of the transverse cervical artery & 6 & I & 2 & 3 & $a=0.035 ; b=0.289$ \\
\hline Thyroid stump & 4 & 2 & I & I & $a=0.893 ; b=0.856$ \\
\hline Skin edge or subcutaneous & 3 & 1 & I & $\mathrm{I}$ & $a=0.523 ; b=0.724$ \\
\hline Diffuse bleeding & 5 & 0 & I & 4 & $a=0.00 I ; b=0.197$ \\
\hline Upper and lower branches of the thyroid artery & 2 & I & I & 0 & $a=0.506 ; b=0.724$ \\
\hline Branch vessel of the upper thymus gland & 3 & I & 0 & 2 & $a=0.144 ; b=0.424$ \\
\hline Roots of the cervical plexus & 2 & 1 & I & 0 & $a=0.506 ; b=0.724$ \\
\hline Broken ends of muscles & 2 & 0 & I & I & $a=0.120 ; b=0.197$ \\
\hline Upper side of neck (lymph node division-2B) & 2 & 1 & 0 & I & $a=0.523 ; b=0.424$ \\
\hline \multicolumn{6}{|l|}{ Processing Method } \\
\hline Local compression plus hemostasis & 3 & 1 & I & 1 & $a=0.523 ; b=0.724$ \\
\hline Bedside hemostasis exploration & 16 & 10 & 4 & 2 & $a=0.563 ; b=0.924$ \\
\hline Hemostasis in the operating room & 24 & 8 & 8 & 8 & $a=0.011 ; b=0.183$ \\
\hline Tracheotomy & 2 & I & 0 & I & $a=0.523 ; b=0.424$ \\
\hline
\end{tabular}

Notes: Ten patients-each had two reasons. a: Obese group vs normal group; b: overweight group vs normal group.

Abbreviations: TPM, thoracic papillary muscle; RLN, recurrent laryngeal nerve.

the patients, proportion of the anterior cervical vein and the transverse carotid artery branch are second and third, respectively.

Most of the 43 patients with PH were treated by exploration and hemostasis in the operating room (55.81\%). Two patients $(4.65 \%)$ were transferred to the operating room for exploration and hemostasis after emergency tracheotomy on the ward; PH in three cases $(6.98 \%)$ was stopped after application of local pressure, bandaging and hemostasis; 16 patients $(37.21 \%)$ were attended to at the bedside for exploration and hemostasis. Eight patients with $\mathrm{PH}$ in the obese group underwent hemostasis in the operating room that was related directly to the difficulty of exploration at the bedside. PH disappeared completely after active treatment, and all patients were discharged from hospital.

\section{Discussion}

In obese patients, exposure of the surgical field is challenging, and the requirements for preoperative evaluation and postoperative care are also greater. According to Smith and Coughlin ${ }^{5}$ and Materazzi et $a{ }^{6}{ }^{6}$ the probability of bleeding after thyroid surgery is $0.1-0.8 \%$, similar to the data in our study $0.58 \%(43 / 7413)$. We also found that 26 (60.47\%) patients developed hemorrhage between $4 \mathrm{~h}$ and
$8 \mathrm{~h}$ after surgery, findings that are also consistent with the observations of Smith and Coughlin ${ }^{5}$ and Materazzi et al, ${ }^{6}$ who found that PH occurred within $12 \mathrm{~h}$.

The most important sequela of hemorrhage after TC surgery is not excessive blood loss, but suffocation due to tracheal compression caused by bleeding in the surgical field. Hence, active prevention preoperatively, complete hemostasis intraoperatively, early detection and timely treatment postoperatively are the key factors to reduce PH risk.

In the present study, two patients with PH had dyspnea, and oxygen saturation in blood continued to decline; after emergency tracheotomy at the bedside, and timely hemostasis in the operating room, their lives were saved. OS at 5 years for the three groups was $90.70 \%$, slightly lower than that reported by Liu et $\mathrm{al}^{13}$ and Farooq et al. ${ }^{14,15}$ This difference may have been due to the late stage of enrolment, older age and other systemic diseases.

Hypertension and CHD were independent risk factors for hemorrhage after TC surgery. Obese patients carry a higher risk of hypertension and CHD than their younger counterparts. Poor control of hypertension in some patients led to large fluctuations of blood pressure after the induction of general anesthesia. Some CHD patients had been taking anticoagulants (e.g., aspirin) for a long time 
(although these drugs had been stopped before surgery) or low-molecular-weight heparin, and some patients had diffuse bleeding, particularly in the surgical area. A low BMI, short operative time, low bleeding volume, and low prevalence of hypoparathyroidism and RLN injury were noted, similar to the findings of Materazzi et $\mathrm{al}^{6}$ and Farooq et al. ${ }^{15}$

The cause and location of bleeding in some patients overlapped (Table 4). The main reason was inappropriate actions by the surgeon (51.16\%), especially with regard to blood vessels. Postoperatively, bleeding from large blood vessels is rare but, if it does occur, it is mainly because the ligation is not tight or high pressure has caused the ligature to fall off. Similar to the viewpoints of several scholars, ${ }^{12,15,16}$ we found only one case of bleeding in the upper thyroid artery. For PH accompanied by other disorders (coagulation dysfunction, Hashimoto's thyroiditis), the suture may not be tight and application of heatbased instruments to stop bleeding may not be thorough. ${ }^{17,18}$ The main patient factors were postoperative nausea, vomiting, coughing and sneezing, which resulted in increased venous return. Most of these problems can be avoided by adequate hemostasis intraoperatively, and active prevention using antiemetics during anesthesia and postoperatively. Some scholars ${ }^{5,11,13}$ have summarized the high-risk factors of hemorrhage after thyroidectomy as use of antithrombotic drugs, advanced age, hyperthyroidism, and neck dissection, all of which can be minimized.

Intraoperative management of obese patients can differ. We suggest that the length of the first incision should not be too short. Also, tissue separation should be achieved under direct vision when opening the white line of the neck under the subcutaneous area. Especially when the upper and lower ends of the white line appear, the branches of the anterior jugular vein should be ligated in time. When closing white lines, the lowest end should be kept at $1-1.5 \mathrm{~cm}$ without suturing to prevent bleeding in the thyroid area. This strategy is not only convenient for observing subcutaneous swelling but also delays the time of dyspnea caused by bleeding, which creates the conditions for exploration and hemostasis. The two patients who underwent tracheotomy were obese but did not have subcutaneous swelling. In both patients, the first symptom was dyspnea. Open exploration revealed that the white line was completely sutured, resulting in hemorrhage in the thyroid area, no drainage to subcutaneous tissue, and the missed possibility of early detection.
The site that bled most readily was a branch of the LRN into the larynx (Table 5). This phenomenon may have been for three main reasons. First, exposure of this site under direct vision is challenging, especially in obese patients. Second, this branch vessel is mostly convoluted and readily missed during ligation. Third, injury to the RLN is a major concern because of its close proximity. We found significant differences between obese and normal groups in terms of the nourishing vein of thoracic papillary muscles (TPMs), branch of the transverse carotid artery, and diffuse hemorrhage, but no significant differences between overweight and normal groups (Table 5). Hemorrhage of the superficial anterior cervical vein was due mainly to injury during the separation of subcutaneous tissue. Hemorrhage in the nourishing vein of the TPMs, branch of the transverse cervical artery, thyroid stump, branch vessel of the upper thymus, roots of the cervical plexus, and broken ends of muscles was caused by incomplete locking of energy devices ${ }^{17,18}$ or absence of ligation. The branch of the internal jugular vein being located at the junction of 2-3 areas, or the position of the external jugular vein into the internal jugular vein being too high (especially if lymph-node dissection was undertaken) were other causes of PH. Surprisingly, bleeding could be caused by negative-pressure suction, especially if a drainage tube was placed at the broken end of a closed blood vessel or skin edge. Two cases of bleeding occurred due to this reason, and it was stopped by adjusting the position of the drainage tube.

Two methods can be used to deal with bleeding in patients with different BMI values (Table 5). The first choice is conservative treatment. If blood flow is slow, or blood flows out intermittently, and the patient does not have obvious dyspnea, local pain or dysphagia, temporary conservative treatment can be adopted (e.g., intravenous injection of hemostatic drugs, fluid infusion, application of local pressure, strengthening drainage). Vital signs (especially oxygen saturation and respiration rate) should be observed closely. Three patients received conservative treatment and achieved good results, similar to the report by Farooq et al. ${ }^{15}$ The second method is exploration and hemostasis. If the BMI is $>28 \mathrm{~kg} / \mathrm{m}^{2}$, or obvious swelling or dyspnea are present, open exploration and hemostasis should be instigated immediately: delay will lead to further deterioration. We suggest aseptic hemostasis in the operating room. However, in an emergency, bedside exploration can be carried out, and the white-line suture must be opened to remove blood clots in the thyroid area. If dyspnea has not been relieved or three concave signs have 
been aggravated, tracheal intubation or tracheotomy should be done immediately to keep the respiratory tract open. If it is too late to intubate, tracheotomy can be undertaken directly. ${ }^{5,13,15,19}$ Two patients underwent bedside tracheotomy and were then transferred to the operating room for hemostasis. Special attention should be paid to full closure around tracheal fistulae to prevent negativepressure air leakage, especially in obese patients.

\section{Conclusions}

Obesity is closely associated with PH in TC patients. Therefore, in obese patients, active prevention preoperatively, complete hemostasis intraoperatively, early detection and timely treatment postoperatively are the key factors to reduce $\mathrm{PH}$ risk.

\section{Ethics}

This study was approved by the Ethics Committee of the Affiliated Tumor Hospital of Zhengzhou University, and patient consent to review their medical records was required by the Ethics Committee of the Affiliated Tumor Hospital of Zhengzhou University. We ensure that all patient data confidentiality and compliance with the Declaration of Helsinki.

\section{Acknowledgments}

Thanks are due to Qigen Fang for assistance with the experiments and to $\mathrm{Xu}$ Zhang for valuable discussion.

\section{Author Contributions}

All authors contributed to data analysis, drafting and revising the article, gave final approval of the version to be published, and agree to be accountable for all aspects of the work.

\section{Funding}

This study was funded by the National Natural Science Foundation of China (81703298, 81402578), Medical Science and Technology Research Project of Henan Province: Joint Co-construction Project (2018020488) and Special Research and Development and Promotion Project of Henan Province: Science and Technology Research Project (192102310354).

\section{Disclosure}

The authors declare that they have no competing interests.

\section{References}

1. Chen W, Zheng R, Baade PD, et al. Cancer statistics in China, 2015. CA Cancer J Clin. 2016;66:115-132. doi:10.3322/caac.21338

2. NCD Risk Factor Collaboration (NCD-RisC). Trends in adult body-mass index in 200 countries from 1975 to 2014: a pooled analysis of 1698 population-based measurement studies with 19.2 million participants. Lancet. 2016;387:1377-1396. doi:10.1016/ S0140-6736(16)30054-X

3. Pappa T, Alevizaki M. Obesity and thyroid cancer: a clinical update. Thyroid. 2014;24:190-199. doi:10.1089/thy.2013.0232

4. Schmid D, Ricci C, Behrens G, Leitzmann MF. Adiposity and risk of thyroid cancer: a systematic review and meta-analysis. Obes Rev. 2015;16:1042-1054. doi:10.1111/obr.12321

5. Smith RB, Coughlin A. Thyroidectomy hemostasis. Otolaryngol Clin North Am. 2016;49:727-748. doi:10.1016/j.otc.2016.03.006

6. Materazzi JG, Ambrosini CE, Fregoli L, et al. Prevention and management of bleeding in thyroid surgery. Gland Surg. 2017;6:510-515. doi: $10.21037 / \mathrm{gs}$

7. Gaurav K, Mishra SK. Electro-operative adjuncts for hemostasis in thyroidectomy. Surgery. 2017;161:1468-1469. doi:10.1016/j.surg.2016. 10.030

8. Tuttle RM, Haugen B, Perrier ND. The updated AJCC/TNM staging system for differentiated and anaplastic thyroid cancer (8th edition): what changed and why? Thyroid. 2017;27:751-756. doi:10.1089/ thy.2017.0102

9. Haugen BR, Alexander EK, Bible KC, et al. 2015 American Thyroid Association management guidelines for adult patients with thyroid nodules and differentiated thyroid cancer: The American Thyroid Association guidelines task force on thyroid nodules and differentiated thyroid cancer. Thyroid. 2016;26:1-133.

10. WHO Expert Consultation. Appropriate body-mass index for Asian populations and its implications for policy and intervention strategies. Lancet. 2004;363:157-163. doi:10.1016/S0140-6736(03)15268-3

11. Kitahara CM, Sosa JA. The changing incidence of thyroid cancer. Nat Rev Endocrinol. 2016;12:646-653. doi:10.1038/nrendo.2016.110

12. Harding T, Gnaneswaran N, Chan S. Risk factors for post-thyroidectomy haematoma. J Laryngol Otol. 2016;130(suppl 1):S20-S25. doi:10.1017/S0022215115003199

13. Liu J, Sun W, Dong W, et al. Risk factors for post-thyroidectomy haemorrhage: a meta-analysis. Eur J Endocrinol. 2017;176:591-602. doi:10.1530/EJE-16-0757

14. Jin J, Phitayakorn R, Wilhelm SM, McHenry CR. Advances in management of thyroid cancer. Curr Probl Surg. 2013;50:241-289. doi:10.1067/j.cpsurg.2013.02.001

15. Farooq MS, Nouraei R, Kaddour H, Saharay M. Patterns, timing and consequences of post-thyroidectomy hemorrhage. Ann R Coll Surg Engl. 2013;99:60-62. doi:10.1308/rcsann.2016.0270

16. Lee HS, Lee BJ, Kim SW, et al. Patterns of post-thyroidectomy hemorrhage. Clin Exp Otorhinolaryngol. 2009;2:72-77. doi:10.3342/ ceo.2009.2.2.72

17. Hammad AY, Deniwar A, Al-Qurayshi Z, Mohamed HE, Rizwan A, Kandil E. A prospective study comparing the efficacy and surgical outcomes of harmonic focus scalpel versus LigaSure small jaw in thyroid and parathyroid surgery. Surg Innov. 2016;23:486-489. doi:10.1177/1553350616639143

18. Applewhite MK, White MG, James BC, et al. Ultrasonic, bipolar, and integrated energy devices: comparing heat spread in collateral tissues. J Surg Res. 2017;207:249-254. doi:10.1016/j.jss.2016.06.077

19. Dionigi G, Wu CW, Kim HY, et al. Safety of energy-based devices for hemostasis in thyroid surgery. Gland Surg. 2016;5:490-494. doi:10.21037/gs.2016.09.01 


\section{Publish your work in this journal}

Cancer Management and Research is an international, peer-reviewed open access journal focusing on cancer research and the optimal use of preventative and integrated treatment interventions to achieve improvec outcomes, enhanced survival and quality of life for the cancer patient.
The manuscript management system is completely online and includes a very quick and fair peer-review system, which is all easy to use. Visit http://www.dovepress.com/testimonials.php to read real quotes from published authors.

Submit your manuscript here: https://www.dovepress.com/cancer-management-and-research-journal 